\title{
Bottom-up Synthesis of Porous NiMo Alloy for Hydrogen Evolution Reaction
}

\author{
Kailong $\mathrm{Hu}^{1}$, Samuel Jeong ${ }^{1}$, Mitsuru Wakisaka ${ }^{2,3}$, Jun-ichi Fujita ${ }^{1}$ and Yoshikazu Ito ${ }^{1,2, * \text { (D) }}$ \\ 1 Institute of Applied Physics, Graduate School of Pure and Applied Sciences, University of Tsukuba, \\ Tsukuba, Ibaraki 305-8573, Japan; kailong_hu@hotmail.com (K.H.); wjl1240@gmail.com (S.J.); \\ fujita@bk.tsukuba.ac.jp (J.-i.F.) \\ 2 PRESTO, Japan Science and Technology Agency, Saitama 332-0012, Japan; wakisaka@yamanashi.ac.jp \\ 3 Graduate School of Engineering, Toyama Prefectural University, 5180 Kurokawa, Imizu, \\ Toyama 939-0398, Japan \\ * Correspondence: ito.yoshikazu.ga@u.tsukuba.ac.jp; Tel.: +81-29-853-5247
}

Received: 15 October 2017; Accepted: 20 January 2018; Published: 23 January 2018

\begin{abstract}
Bottom-up synthesis of porous NiMo alloy reduced by $\mathrm{NiMoO}_{4}$ nanofibers was systematically investigated to fabricate non-noble metal porous electrodes for hydrogen production. The different annealing temperatures of $\mathrm{NiMoO}_{4}$ nanofibers under hydrogen atmosphere reveal that the $950{ }^{\circ} \mathrm{C}$ annealing temperature is key for producing bicontinuous porous NiMo alloy without oxide phases. The porous NiMo alloy acts as a cathode in electrical water splitting, which demonstrates not only almost identical catalytic activity with commercial $\mathrm{Pt} / \mathrm{C}$ in $1.0 \mathrm{M} \mathrm{KOH}$ solution, but also superb stability for 12 days at an electrode potential of $-200 \mathrm{mV}$ vs. reversible hydrogen electrode (RHE).
\end{abstract}

Keywords: nanoporous; NiMo; non-noble metal catalyst; hydrogen evolution

\section{Introduction}

Nanoporous metals are key materials for energy engineering fields because of outstanding conductivity, bi-continuous open porous structures with tunable porosity, large surface area, excellent catalytic activities and high mechanical strength [1,2]. Recently, the study of nanoporous non-precious metals has been focused as electrodes and catalysts such as supercapacitors [3,4], Li-air batteries [5,6], fuel cells and water electrolysis $[7,8]$, showing great potentials as precious metal-free electrodes. The fabrication process of nanoporous metals employs a dealloying method in which the solid solution alloy of precious metal and non-precious metal is electrochemically corroded in acidic electrolytes [1]. However, in this method, the alloy combinations in the dealloying method is very limited and the non-precious metal of $\mathrm{Ni}, \mathrm{Fe}$ and $\mathrm{Cu}$ is usually the one to be removed from the alloy, forming precious metal-based nanoporous structures. Therefore, the desirable design of non-precious metal has been explored to expand their applications.

Nanoporous non-precious metals have been synthesized by bottom-up approaches such as nanoparticle-sintering $[9,10]$ and reduction of metal oxides [11,12]. In particular, the reduction of metal oxide is a powerful method to prepare nanoporous non-precious metal. One of the most attractive porous metals is NiMo alloy which is known as one of the best hydrogen evolution electrode catalyst for cost-effective and highly efficient hydrogen production in water electrolysis $[13,14]$. Although different kinds of NiMo alloy porous morphologies were investigated such as HER catalysts including $\mathrm{Ni}_{4} \mathrm{Mo}$ [15], NiMo nanopowder [16], NiMo nanowire [17], the performances show that HER performance is not very enhanced due to the absence of bicontinuous and monolithic porous structures. Indeed, the $\mathrm{Ni}$ foam supported $\mathrm{Ni}_{4} \mathrm{Mo}$ nanoparticles, and the three-dimensional $\mathrm{NiMo}$ nanowires significantly improved their HER activities. This means that bicontinuous and monolithic 3D electrode catalysts bring high reaction kinetics. Therefore, NiMo alloy with bicontinuous open 
porous 3D structure can be a central electrode catalyst for electrical water splitting combined with renewable energy such as wind, water and solar energies to produce eco-friendly hydrogen production without any carbon emission.

In this study, we have systematically investigated porous NiMo alloy with different annealing temperatures from 400 to $950{ }^{\circ} \mathrm{C}$ to understand the formation of porous structures by reduction under hydrogen atmosphere. Moreover, the electrochemical performances of resulting porous NiMo alloy samples were tested in $1 \mathrm{M} \mathrm{KOH}$ electrolyte with the comparison of the best catalyst of platinum (Pt). The durability test in $1 \mathrm{M} \mathrm{KOH}$ electrolyte was further carried out by cyclic voltammetry and chronoamperometry measurements.

\section{Materials and Methods}

Preparation of $\mathrm{NiMoO}_{4}$ nanofibers. $\mathrm{NiMoO}_{4}$ nanofibers, synthesized by a standard hydrothermal method [18,19], were used as precursors to obtain 3D porous NiMo alloy through a reductive annealing system. $2.5 \mathrm{mmol} \mathrm{NiCl} \cdot 6 \mathrm{H}_{2} \mathrm{O}(98 \%$ purity, Wako Pure Chemical Industries, Osaka, Japan) and $2.5 \mathrm{mmol} \mathrm{Na} \mathrm{MoO}_{4} \cdot 2 \mathrm{H}_{2} \mathrm{O}(99 \%$ purity, Wako Pure Chemical Industries, Osaka, Japan) were dissolved in $30 \mathrm{~mL}$ deionized water, and then was transferred into a $50 \mathrm{~mL}$ Teflon coated stainless autoclave, which was kept at $150{ }^{\circ} \mathrm{C}$ for $12 \mathrm{~h}$. After the autoclave cooling down to room temperature, the as-prepared $\mathrm{NiMoO}_{4}$ nanofibers were washed by deionized water several times with a centrifuge, and kept in deionized water.

Preparation of porous NiMo alloy. The $\mathrm{NiMoO}_{4}$ nanofiber solution was dropped on $\mathrm{Cu}$ sheets, and dried naturally for one day. The dried $\mathrm{NiMoO}_{4}(5.0 \mathrm{~g})$ was put into the center of a quartz tube $\left(\varphi 30 \times \varphi 27 \times 1000 \mathrm{~mm}^{3}\right)$ furnace. The $\mathrm{NiMoO}_{4}$ was reduced at various temperatures from 400 to $950{ }^{\circ} \mathrm{C}$ for $20 \mathrm{~min}$ under the mixed atmosphere of hydrogen $(100 \mathrm{sccm})$ and argon $(200 \mathrm{sccm})$ to reduce oxides for porous structure formation. After the annealing, the resulting reduced samples were removed from the $\mathrm{Cu}$ sheets for measurements.

Imaging and spectroscopic characterization. The morphology and microstructure of 3D NiMo alloy were characterized by a scanning electron microscope (SEM, JSM-4300, JEOL, Tokyo, Japan). The X-ray diffraction (XRD) was carried out using a Rigaku SmartLab 9MTP diffractometer (Rigaku, Tokyo, Japan) with a $9.0 \mathrm{~kW}$ rotating anode generator ( $\mathrm{Cu} \mathrm{K} \alpha 1$ radiation; $\lambda=1.5406 \AA$ ). The $\mathrm{X}$-ray photoelectron spectroscopy (XPS, AXIS ultra DLD, Shimazu, Tokyo, Japan) with Al K $\alpha$ and X-ray monochromator was utilized for surface chemical compositions analysis. The surface area of porous NiMo sample was measured by the Brunauer-Emmett-Teller (BET) methods using a BELSORP-mini II (BEL Inc., Osaka, Japan) at $77.0 \mathrm{~K}$. The sample was heated at $120^{\circ} \mathrm{C}$ under vacuum for $48 \mathrm{~h}$ before the measurements.

Electrochemical characterizations. Hydrodynamic voltammetry for HER and electrochemical impedance spectroscopy (EIS) were conducted using an electrochemical workstation (VSP-300, Bio-Logic Science Instruments, Seyssinet-Pariset, France) equipped with a rotation disk electrode (RDE, $5 \mathrm{~mm}$ diameter glassy carbon, Hokuto Denko Corp., Tokyo, Japan). A graphite plate, an Ag/ AgCl electrode (Hokuto Denko Corp., Tokyo, Japan) and the porous NiMo samples (5 mg) dispersed on the glassy carbon served as the counter electrode, the reference electrode and the working electrode, respectively. The porous NiMo samples and $10 \mathrm{wt} \% \mathrm{Pt} / \mathrm{C}$ (Sigma-Ardrich, Tokyo, Japan) were dispersed uniformly on the surface of the glassy carbon electrode using Nafion (5\% DE521 CS type, Wako Pure Chemical Industries, Osaka, Japan) as a binder. The $\mathrm{Ag} / \mathrm{AgCl}$ electrode was compared with a fresh $\mathrm{Ag} / \mathrm{AgCl}$ electrode to check the differences of potential before use. All potentials were calculated with respect to reversible hydrogen electrode (RHE) using the equation: $E(\mathrm{RHE})=E(\mathrm{Ag} / \mathrm{AgCl})+0.0591 \times \mathrm{pH}+0.1976$. The cyclic voltammetry $(\mathrm{CV})$ measurements after several cycles were recorded from $-250 \mathrm{mV}$ to $+100 \mathrm{mV}$ (vs. RHE) at a sweep rate of $10 \mathrm{mV} / \mathrm{s}$ in $1 \mathrm{M}$ $\mathrm{KOH}$ electrolyte $(\mathrm{pH}=13.9)$ deaerated with $\mathrm{Ar}(99.999 \%)$ with disk rotation speed of $1600 \mathrm{rpm}$ to remove generated hydrogen bubbles. The electrode potential in the hydrodynamic voltammogram was automatically iR-compensated with the Ohmic resistance measured at $+200 \mathrm{mV}$ (vs. RHE). The EIS 
measurement was carried out at $-200 \mathrm{mV}$ (vs. RHE) with an amplitude of $50 \mathrm{mV}$. The durability of the electrodes was tested by potential cycling between $-250 \mathrm{mV}$ to $+100 \mathrm{mV}$ (vs. RHE) at $10 \mathrm{mV} / \mathrm{s}$. The electrolyte after $2000 \mathrm{CV}$ cycle test was collected and analyzed through ICP-OES (Thermo Fisher Scientific IRIS Advantage DUO, Thermo Fisher Scientific Japan, Yokohama, Japan) to determine the leaching amount from NiMo catalyst.

\section{Results and Discussion}

The fabrication process of 3D porous NiMo alloy, illustrated in Figure 1, was divided into two main procedures. Firstly, the $\mathrm{NiMoO}_{4}$ nanofibers, the precursor of porous NiMo, were synthesized through a standard hydrothermal method at $150{ }^{\circ} \mathrm{C}$ for $12 \mathrm{~h}$. Secondly, the resulting $\mathrm{NiMoO}_{4}$ nanofibers dropped on $\mathrm{Cu}$ sheets and inserted into a quartz tube furnace were annealed at $400-950{ }^{\circ} \mathrm{C}$ for $20 \mathrm{~min}$ under the mixed gases of hydrogen and argon to reduce the oxidized precursor. After the furnace cooling down to room temperature, the annealed $\mathrm{NiMoO}_{4}$ samples were peeled off from the Cu sheets for characterizations and measurements. Moreover, the sheet area easily reached to $2 \mathrm{~cm}^{2}$ (Figure 1 ) when the area of $\mathrm{Cu}$ sheet was tuned.

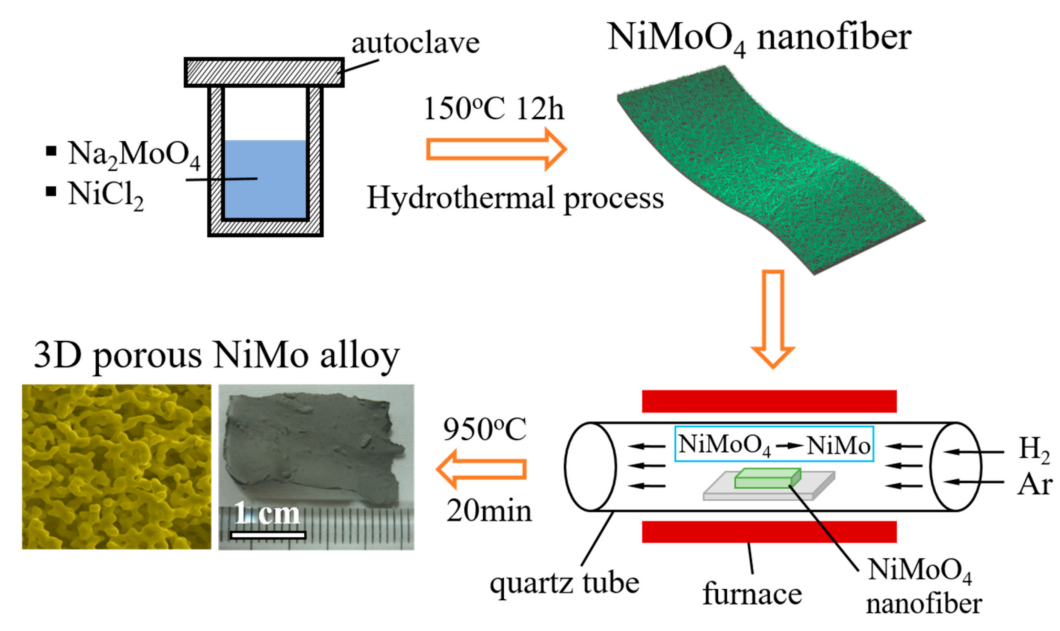

Figure 1. Schematic illustration of the synthesis process of 3D porous NiMo alloy.

The morphologies of annealed $\mathrm{NiMoO}_{4}$ samples were investigated to reveal the formation process of porous structures with scanning electron microscope (SEM) measurements. The nanofiber structure was kept at low temperatures of $0-500{ }^{\circ} \mathrm{C}$ (Figure $2 \mathrm{a}-\mathrm{c}$ ), and some nanoparticles were generated on the surface of nanofibers at $500{ }^{\circ} \mathrm{C}$ due to the reduction of $\mathrm{NiMoO}_{4}$ nanofibers (inset of Figure $2 \mathrm{c}$ ). When the temperature reached $600{ }^{\circ} \mathrm{C}$, the generated nanoparticles started to fuse and reconstruct each other to be energetically stable due to the high geometric potential at the nanoparticle state (Figure 2d). The pristine nanofiber structures totally disappeared at $700{ }^{\circ} \mathrm{C}$ and the ligaments in the porous structures were gradually formed with pore size less than $100 \mathrm{~nm}$ (Figure 2e). The 3D open porous structures were developed and the porous structures became bicontinuous and interconnected above $800{ }^{\circ} \mathrm{C}$ (Figure 2f). The porous structures were well developed and the pore size increased from tens of nanometers to a few hundred nanometers with the temperature ranging from 800 to $950{ }^{\circ} \mathrm{C}$ (Figure $2 \mathrm{~g}, \mathrm{~h}$ ). The view of the cross-section of sample annealed at $950{ }^{\circ} \mathrm{C}$ showed the open and bicontinuous structures were well preserved in the inside of the sample sheets (Figure 2i).

The crystal structures of annealed $\mathrm{NiMoO}_{4}$ samples were studied by X-ray diffraction (XRD) measurements (Figure 3a). The pristine $\mathrm{NiMoO}_{4}$ nanofibers and sample annealed at $400{ }^{\circ} \mathrm{C}$ matched well with the $\mathrm{NiMoO}_{4} \cdot x \mathrm{H}_{2} \mathrm{O}$ (JCPDS \#13-0128) (Figure S1). When the annealing temperature ranges between 500 and $600{ }^{\circ} \mathrm{C}$, the obtained peaks were well assigned to $\mathrm{NiMoO}_{4}$ (JCPDS \#33-0948). This can be explained with the complete removal of crystal water at 500-600 ${ }^{\circ} \mathrm{C}$. At $700{ }^{\circ} \mathrm{C}$, some $\mathrm{NiMoO}_{4}$ were reduced and decomposed under the reducing atmosphere, partly forming $\mathrm{NiO}$ (JCPDS \#71-1179) 
and $\mathrm{MoO}_{2}$ (JCPDS \#65-5787) (Figure S2). Above $800^{\circ} \mathrm{C}$, the composition of NiMo (JCPDS \#48-1745), $\mathrm{Ni}_{4} \mathrm{Mo}$ (JCPDS \#65-5480), and pure Mo (JCPDS \#42-1120) were gradually generated and oxidized species of $\mathrm{NiO}$ and $\mathrm{MoO}_{2}$ were gradually reduced. It is worth noting that the reduction of $\mathrm{NiMoO}_{4}$ requires $800{ }^{\circ} \mathrm{C}$ and reduction of $\mathrm{MoO}_{2}$ requires $950{ }^{\circ} \mathrm{C}$. Thus, the sample annealed at $950{ }^{\circ} \mathrm{C}$ only obtains NiMo with a certain amount of $\mathrm{Ni}_{4} \mathrm{Mo}$ alloys. In addition, an overview of XRD patterns of pristine $\mathrm{NiMoO}_{4}$ and samples annealed at $400-950{ }^{\circ} \mathrm{C}$ is displayed in Figure S3. The specific surface area of the porous NiMo annealed at $950{ }^{\circ} \mathrm{C}$ was measured by the BET methods. The surface area was estimated as $2.81 \mathrm{~m}^{2} / \mathrm{g}$ (Figure S4).
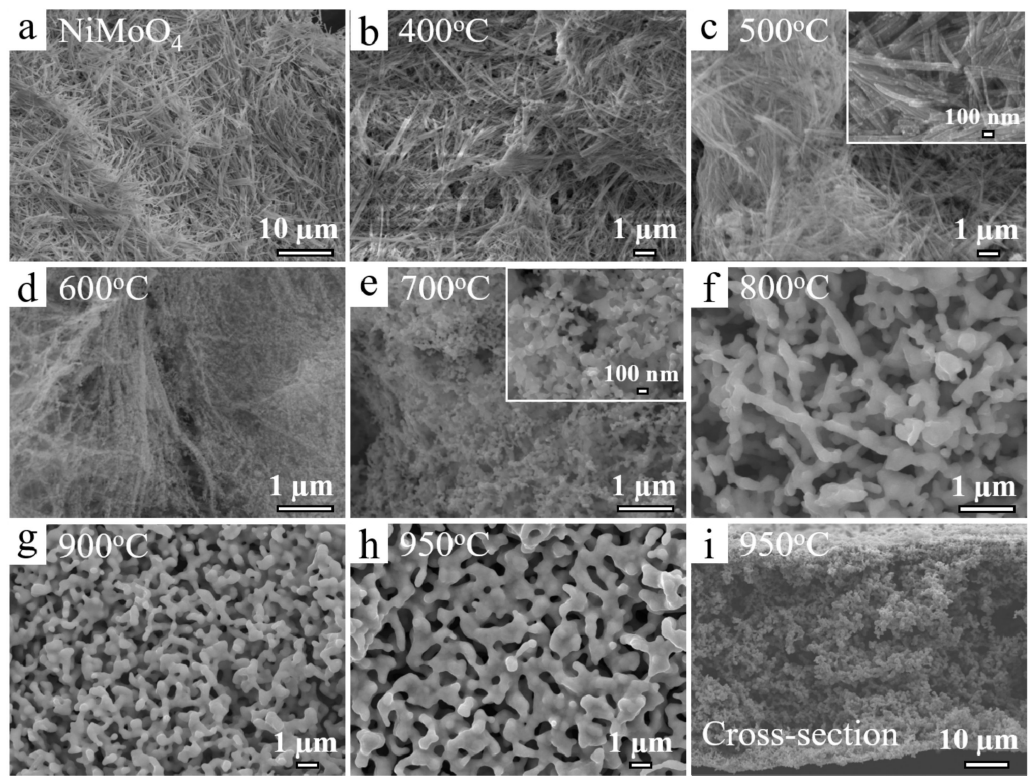

Figure 2. SEM images of (a) pristine $\mathrm{NiMoO}_{4}$ nanofiber; $(\mathbf{b}-\mathbf{i})$ temperature effect of $3 \mathrm{D}$ porous structure formation on samples annealed at $400-950{ }^{\circ} \mathrm{C}$. The insets in (c,e) show high resolution SEM images.

The surface chemical compositions of porous $\mathrm{NiMo}$ and $\mathrm{Ni}_{4} \mathrm{Mo}$ alloy samples annealed at 900 and $950{ }^{\circ} \mathrm{C}$ were tested by X-ray photoelectron spectroscope (XPS) measurements. The high-resolution $\mathrm{Ni} 2 \mathrm{p}$ spectrum of the sample annealed at $900{ }^{\circ} \mathrm{C}$ reveals that the main peaks are assigned to $\mathrm{Ni}$ $(852.6 \mathrm{eV}, 869.6 \mathrm{eV})$ and $\mathrm{NiO}(855.9 \mathrm{eV}, 873.6 \mathrm{eV})$, while the $\mathrm{NiO}$ peaks of the sample annealed at $950{ }^{\circ} \mathrm{C}$ are negligibly small (Figure $3 b, \mathrm{~d}$ ) [20-22]. These results further indicate that Ni oxides were completely reduced at $950{ }^{\circ} \mathrm{C}$. The high-resolution Mo $3 \mathrm{~d}$ spectrum of samples annealed at $900{ }^{\circ} \mathrm{C}$ were deconvoluted into six distinct peaks at $227.4 \mathrm{eV}, 230.6 \mathrm{eV}, 228.5 \mathrm{eV}, 231.6 \mathrm{eV}, 232.1 \mathrm{eV}$ and $235.2 \mathrm{eV}$, assigning to $\mathrm{NiMo}, \mathrm{Ni}_{4} \mathrm{Mo}$ and Mo oxide, showing alloy and oxidized surface state (Figure 3c) [23-25]. The sample annealed at $950{ }^{\circ} \mathrm{C}$ presents major NiMo (94.4 at \%) with negligible $\mathrm{Ni}_{4} \mathrm{Mo}(1.5$ at \%) and Mo oxide on the surface, further confirming the almost complete reduction of Mo oxide (4.1 at \%, probably oxidized during the transfer to XPS measurements) at $950{ }^{\circ} \mathrm{C}$ (Figure 3e). These XPS results are in good agreement with the XRD results. Considering XRD and XPS results during the reduction process, the following sequential transformations are proposed: (1) the reduction of pristine $\mathrm{NiMoO}_{4}$ to partly-reduced $\mathrm{NiMoO}_{4}$ nanoparticles; (2) the reconstruction and fusion of the further-reduced $\mathrm{NiMoO}_{4}$ nanoparticles to decrease the surface energy; and (3) the complete reduction of $\mathrm{NiMoO}_{4}$ nanoparticles for the formation of ligaments into porous NiMo structures, developing 3D porous NiMo alloy.

The samples with different annealing temperatures of $800{ }^{\circ} \mathrm{C}, 900{ }^{\circ} \mathrm{C}$ and $950{ }^{\circ} \mathrm{C}$ (abbreviated as NiMo- $800{ }^{\circ} \mathrm{C}$, NiMo- $900{ }^{\circ} \mathrm{C}$ and NiMo-950 ${ }^{\circ} \mathrm{C}$ ) with the comparison of commercial $10 \mathrm{wt} \% \mathrm{Pt} / \mathrm{C}$ and the pristine $\mathrm{NiMoO}_{4}$ nanofibers were tested in $1 \mathrm{M} \mathrm{KOH}$ solution to investigate the catalytic HER activities (Figure 4a). The polarization curve of NiMo- $950{ }^{\circ} \mathrm{C}$ exhibits a Pt-like HER activity, 
reaching a current density of $10 \mathrm{~mA} / \mathrm{cm}^{2}$ at an overpotential of $18 \mathrm{mV}$, which is only $2 \mathrm{mV}$ larger than the value achieved by $10 \mathrm{wt} \% \mathrm{Pt} / \mathrm{C}$. Turnover frequency (TOF) normalized by the BET surface area at an electrode potential of $-100 \mathrm{mV}$ (vs. RHE) was roughly estimated and the value was $0.84 \mathrm{H}_{2} \mathrm{~s}^{-1}$ for NiMo-950 ${ }^{\circ} \mathrm{C}$ sample and the TOF value was relatively higher reported NiMo electrode (Table S1). This means that the intrinsic catalyst activity of the NiMo- $950{ }^{\circ} \mathrm{C}$ sample was enhanced by the bi-continuous porous structures. The NiMo- $900{ }^{\circ} \mathrm{C}$ and NiMo- $800{ }^{\circ} \mathrm{C}$ reveal a gradual declining trend of HER catalytic activity, which achieves $10 \mathrm{~mA} / \mathrm{cm}^{2}$ at an overpotential of $66 \mathrm{mV}$ and $182 \mathrm{mV}$. This decline indicates that the existence of Mo oxide and Ni oxide dramatically interferes with HER processes, and the HER activity can be greatly enhanced only with the complete reduction of the oxides at $950{ }^{\circ} \mathrm{C}$. Indeed, the fully oxidized $\mathrm{NiMoO}_{4}$ nanofiber exhibits no HER catalytic activity. The Tafel plots estimated from the polarization curves (Figure $4 \mathrm{~b}$ ) show that the NiMo- $950{ }^{\circ} \mathrm{C}$ achieves a Tafel slope of $36 \mathrm{mV} /$ decade and $10 \mathrm{wt} \% \mathrm{Pt} / \mathrm{C}$ (loading amount: $1 \mathrm{mg}$ ) exhibits $30 \mathrm{mV} /$ decade. Therefore, the Heyrovsky desorption process $\left(\mathrm{H}_{2} \mathrm{O}+\mathrm{e}^{-}+\mathrm{H}^{*} \rightarrow \mathrm{H}_{2}+\mathrm{OH}^{-}\right)$, where $\mathrm{H}^{*}$ represents adsorbed $\mathrm{H}$ atom on catalytic site ${ }^{*}$ ) could be the rate determining step for the NiMo- $950{ }^{\circ} \mathrm{C}$ in $1 \mathrm{M}$ $\mathrm{KOH}$ electrolyte [26]. The Tafel slopes of NiMo-900 ${ }^{\circ} \mathrm{C}$ and NiMo- $800{ }^{\circ} \mathrm{C}$ are $72 \mathrm{mV} /$ decade and $147 \mathrm{mV} /$ decade, indicating the mixed Volmer-Heyrovsky process $\left(\mathrm{H}_{2} \mathrm{O}+\mathrm{e}^{-}+\mathrm{H}^{*} \rightarrow \mathrm{H}_{2}+\mathrm{OH}^{-}\right.$and $\mathrm{H}_{2} \mathrm{O}+\mathrm{e}^{-} \rightarrow \mathrm{H}^{*}+\mathrm{OH}^{-}$) are the corresponding rate determining steps [27,28]. The EIS measurements were further carried out to measure the charge-transfer resistances $\left(R_{\mathrm{ct}}\right)$ of the porous NiMo alloys at an overpotential of $200 \mathrm{mV}$ vs. RHE (Figure 4c). The internal resistances of NiMo- $800{ }^{\circ} \mathrm{C}$, NiMo- $900{ }^{\circ} \mathrm{C}$ and NiMo- $950{ }^{\circ} \mathrm{C}$ are almost the same value of $5 \Omega$. The NiMo- $950{ }^{\circ} \mathrm{C}$ exhibits quite low $R_{\mathrm{ct}}$ value of $7.9 \Omega$, which far lower than the $19.8 \Omega$ for NiMo- $900{ }^{\circ} \mathrm{C}$ and the $26.5 \Omega$ for NiMo- $800{ }^{\circ} \mathrm{C}$, confirming more efficient reaction kinetics of the NiMo- $950{ }^{\circ} \mathrm{C}$ sample. All electrochemical properties are listed in Table S1.
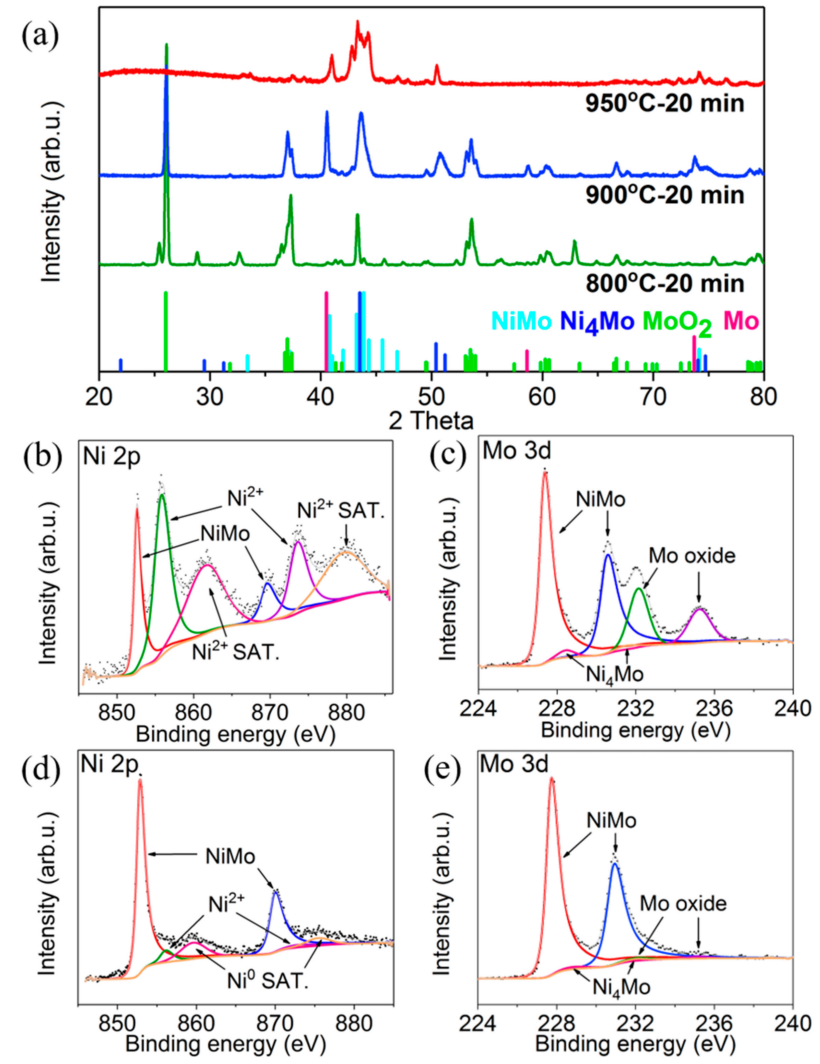

Figure 3. (a) XRD patterns of samples annealed at 800,900 and $950{ }^{\circ} \mathrm{C}$. High-resolution XPS spectra of nickel $2 \mathrm{p}$ and molybdenum $3 \mathrm{~d}$ spectra on porous NiMo samples annealed at $(\mathbf{b}, \mathbf{c}) 900{ }^{\circ} \mathrm{C}$ for $20 \mathrm{~min}$ and (d,e) $950{ }^{\circ} \mathrm{C}$ for $20 \mathrm{~min}$. 

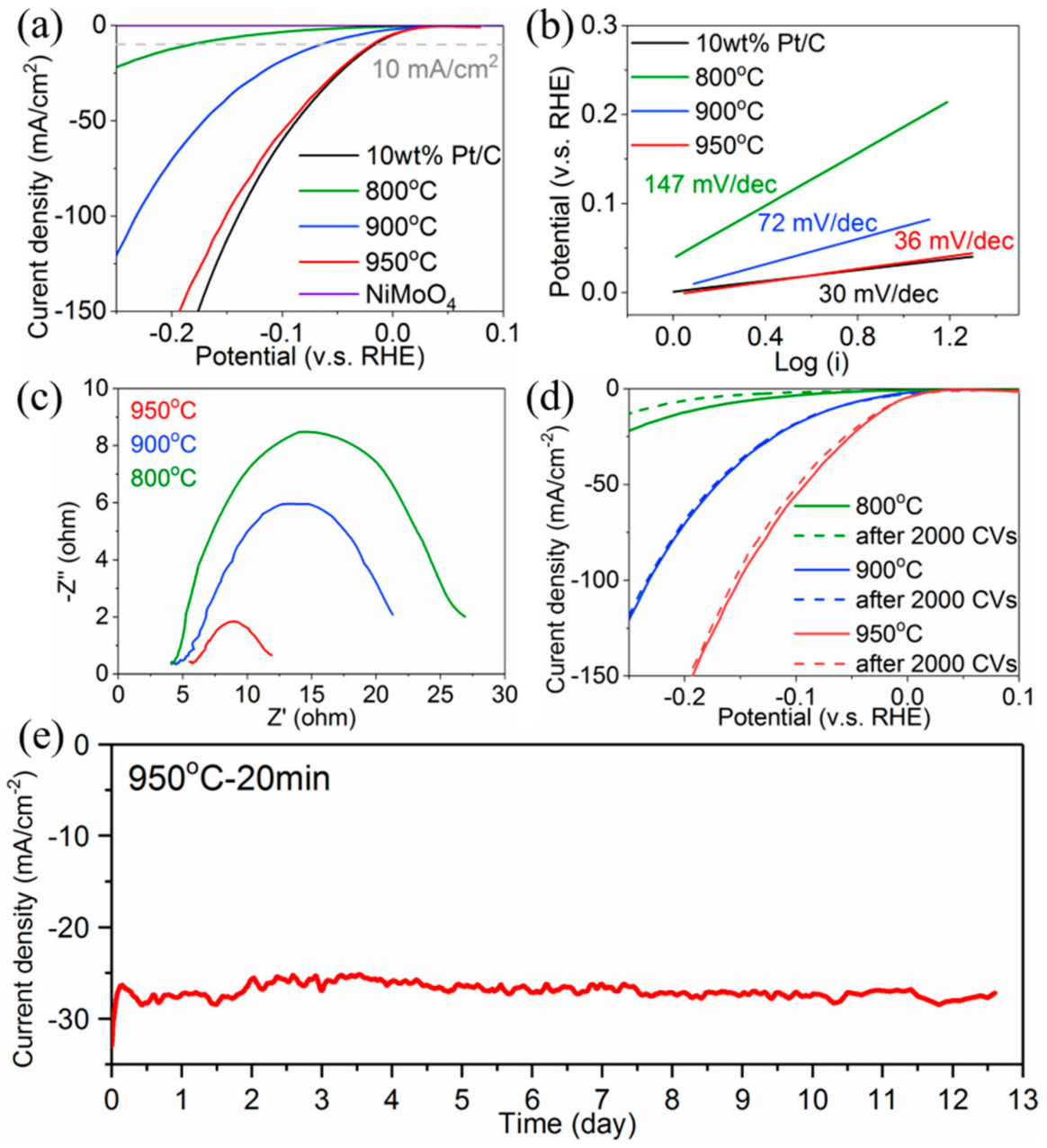

Figure 4. (a) The HER polarization curves of porous NiMo samples annealed at 800, 900 and $950{ }^{\circ} \mathrm{C}$, pristine $\mathrm{NiMoO}_{4}$ nanofibers and $10 \mathrm{wt} \% \mathrm{Pt} / \mathrm{C}$. (b) Corresponding Tafel plots from (a). (c) Electrochemical impedance spectroscopy of porous NiMo samples annealed at 800, 900 and $950{ }^{\circ} \mathrm{C}$ at overpotential of $200 \mathrm{mV}$ vs. RHE. (d) Polarization curves of porous NiMo samples annealed at 800, 900 and $950{ }^{\circ} \mathrm{C}$ before and after $2000 \mathrm{CV}$ cycles. (e) Durability test of porous NiMo annealed at $950{ }^{\circ} \mathrm{C}$ at overpotential of $200 \mathrm{mV}$ by chronoamperometry.

Long-term durability is an important criterion for HER cathodes. The CV and chronoamperometry (CA) measurements were utilized to investigate the stability of porous NiMo alloy at an electrode potential of $-200 \mathrm{mV}$ (vs. RHE) in $1 \mathrm{M} \mathrm{KOH}$ electrolyte. The polarization curves of NiMo- $900{ }^{\circ} \mathrm{C}$ and NiMo- $950{ }^{\circ} \mathrm{C}$ after 2000 cycles exhibit extremely high durability (Figure 4d). The overpotential of NiMo- $950{ }^{\circ} \mathrm{C}$ at $100 \mathrm{~mA} / \mathrm{cm}^{2}$ only increases by $5 \mathrm{mV}$ (150 to $155 \mathrm{mV}$ ) after the $2000 \mathrm{CV}$ cycles. During the CA measurement (Figure 4e), the NiMo-950 ${ }^{\circ} \mathrm{C}$ sample (loading amount: $1 \mathrm{mg}$ ) keeps original performances of $27 \mathrm{~mA} / \mathrm{cm}^{2}$ for 12.5 days at overpotential of $200 \mathrm{mV}$. A rotating disk electrode was not used for the CA test, resulting in some bubbles blocking the surface and a slight decrease of the current density. To understand the superb HER performances and chemical stability, the SEM images of the NiMo- $950{ }^{\circ} \mathrm{C}$ sample after $2000 \mathrm{CV}$ cycles were investigated. The bicontinuous porous structure was well preserved in $1 \mathrm{M} \mathrm{KOH}$ electrolyte (Figure 5). In addition, the ICP-OES was used to investigate the leaching amount of the NiMo electrode after 2000 cycle test. The results reveal that the dissolution amount of $\mathrm{Ni}$ and $\mathrm{Mo}$ is less than 0.6 at \% and 0.3 at \% (under the detection limit), which further confirms the prominent stability. Thus, chemically stable and well-crystalized porous NiMo- $950{ }^{\circ} \mathrm{C}$ alloy electrode plays an important role in outstanding HER performances. 

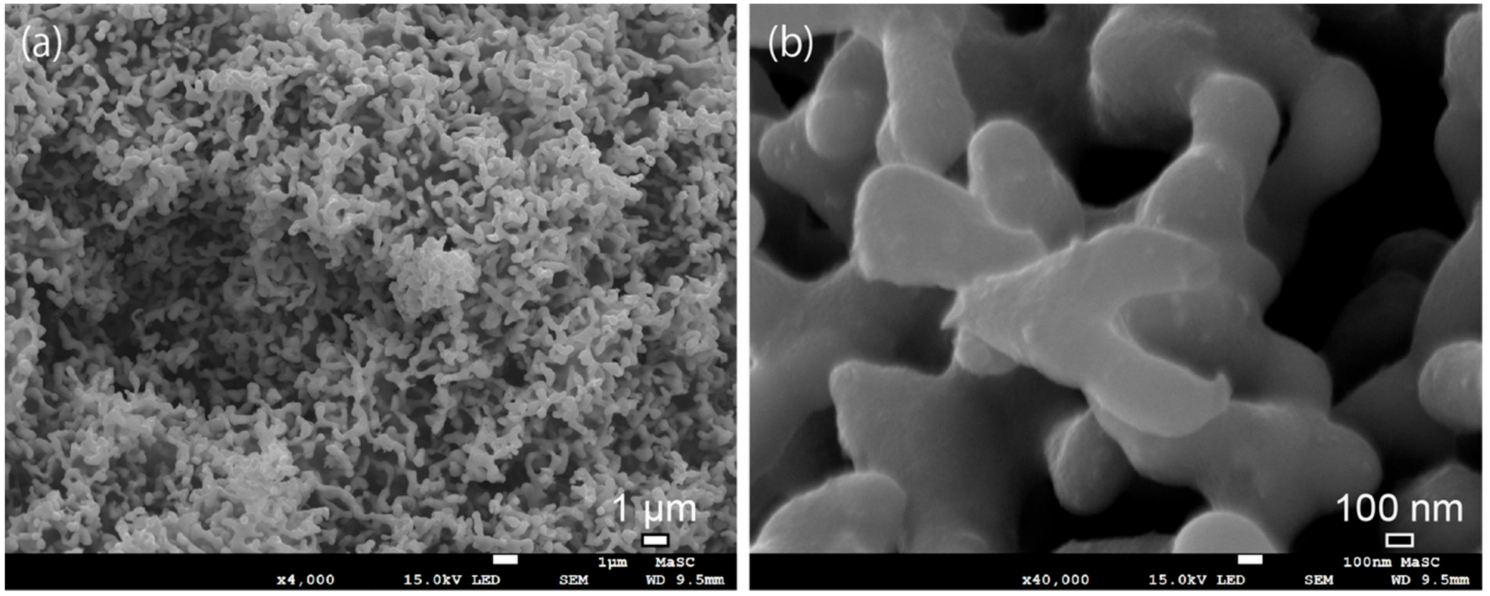

Figure 5. (a) Overview and (b) close-up images of porous NiMo samples annealed at $950{ }^{\circ} \mathrm{C}$ after 2000 CV cycles.

\section{Conclusions}

We have demonstrated the formation of porous NiMo alloy with systematic annealing temperatures from 400 to $950{ }^{\circ} \mathrm{C}$. The formation of porous structures requires $800{ }^{\circ} \mathrm{C}$, and the complete reduction of Mo oxide species requires $950{ }^{\circ} \mathrm{C}$ annealing temperature. The bi-continuous and conductive porous NiMo alloys with larger surface area can enhance intrinsic catalyst activity and would be employed as cathodes for electrical water splitting without losing their catalytic abilities in $1 \mathrm{M} \mathrm{KOH}$ electrolyte for 12.5 days. Such non-noble porous metal alloys could be good replacements for noble metals such as $\mathrm{Pt}$, which has been one of the undue barriers to sustaining worldwide use due to high price and low world supply. Therefore, the development and study of non-noble porous metals as low-cost, earth-abundant HER catalysts offers hopeful alternatives to Pt-based catalysts to achieve hydrogen societies.

Supplementary Materials: The following are available online at http://www.mdpi.com/xxx/s1, Figure S1: The XRD patterns of pristine $\mathrm{NiMoO}_{4}$ and samples annealed at $400{ }^{\circ} \mathrm{C}$ and $500{ }^{\circ} \mathrm{C}$ for 20 min, Figure S2: The XRD patterns of samples annealed at $600{ }^{\circ} \mathrm{C}$ and $700{ }^{\circ} \mathrm{C}$ for $20 \mathrm{~min}$, Figure S3: The overview of XRD patterns of pristine $\mathrm{NiMoO}_{4}$ and samples annealed at temperature ranging from 400 to $950{ }^{\circ} \mathrm{C}$ for 20 min, Figure S4: Nitrogen absorption and desorption measurements of porous NiMo alloy annealed at $950{ }^{\circ} \mathrm{C}$ for $20 \mathrm{~min}$, Table S1: The HER performances of porous NiMo alloy and other reported catalysts.

Acknowledgments: We thank Kazuyo Omura at the Institute for Material Research in Tohoku University for XPS measurements. This work was sponsored by JST-PRESTO “Creation of Innovative Core Technology for Manufacture and Use of Energy Carriers from Renewable Energy" (JPMJPR1541, JPMJPR1444); JSPS KAKENHI Grant Number JP15H05473, JP23246063, JP15H02195, JP15K13717); World Premier International Research Center Initiative (WPI), MEXT, Japan; Japanese Government (MONBUKAGAKUSHO: MEXT) Scholarship.

Author Contributions: Kailong Hu, Samuel Jeong and Yoshikazu Ito fabricated samples and conducted SEM characterizations. Yoshikazu Ito and Kailong Hu performed electrochemical tests. Kailong Hu, Mitsuru Wakisaka, Jun-ichi Fujita and Yoshikazu Ito conducted data analysis and data interpretation. Kailong Hu and Yoshikazu Ito wrote the paper.

Conflicts of Interest: The authors declare no conflict of interest.

\section{References}

1. Ding, Y.; Chen, M.W. Nanoporous metals for catalytic and optical applications. MRS Bull. 2009, 34, 569-576. [CrossRef]

2. Weissmüller, J.; Newman, R.C.; Jin, H.J.; Hodge, A.M.; Kysar, J.W. Nanoporous metals by alloy corrosion: Formation and mechanical properties. MRS Bull. 2009, 34, 577-586. [CrossRef]

3. Qiu, H.J.; Ito, Y.; Chen, M.W. Hierarchical nanoporous nickel alloy as three-dimensional electrodes for high-efficiency energy storage. Scr. Mater. 2014, 89, 69-72. [CrossRef] 
4. Qiu, H.J.; Kang, J.L.; Liu, P.; Hirata, A.; Fujita, T.; Chen, M.W. Fabrication of large-scale nanoporous nickel with a tunable pore size for energy storage. J. Power Sources 2014, 247, 896-905. [CrossRef]

5. Guo, X.W.; Han, J.H.; Liu, P.; Ito, Y.; Hirata, A.; Chen, M.W. Graphene@Nanoporous nickel cathode for Li-O batteries. ChemNanoMat 2016, 2, 176-181. [CrossRef]

6. Guo, X.W.; Liu, P.; Han, J.H.; Ito, Y.; Hirata, A.; Fujita, T.; Chen, M.W. 3D nanoporous nitrogen-doped graphene with encapsulated $\mathrm{RuO}_{2}$ nanoparticles for $\mathrm{Li}-\mathrm{O}_{2}$ batteries. Adv. Mater. 2015, 27, 6137-6143. [CrossRef] [PubMed]

7. Linic, S.; Christopher, P.; Ingram, D.B. Plasmonic-metal nanostructures for efficient conversion of solar to chemical energy. Nat. Mater. 2011, 10, 911-921. [CrossRef] [PubMed]

8. Artero, V.; Kerlidou, M.C.; Fontecave, M. Splitting water with cobalt. Angew. Chem. Int. Ed. Engl. 2011, 50, 7238-7266. [CrossRef] [PubMed]

9. Ito, Y.; Izumi, M.; Hojo, D.; Wakisaka, M.; Aida, T.; Adschiri, T. One-step nanoporous structure formation using $\mathrm{NiO}$ nanoparticles: Pore size control and pore size dependence of hydrogen evolution reaction. Chem. Lett. 2017, 46, 267-270. [CrossRef]

10. Hansen, T.W.; DeLaRiva, A.T.; Challa, S.R.; Datye, A.K. Sintering of catalytic nanoparticles: Particle migration or ostwald ripening? Acc. Chem. Res. 2013, 46, 1720-1730. [CrossRef] [PubMed]

11. Zhang, J.; Wang, T.; Liu, P.; Liao, Z.Q.; Liu, S.H.; Zhuang, X.D.; Chen, M.W.; Zschech, E.; Feng, X.L. Efficient hydrogen production on $\mathrm{MoNi}_{4}$ electrocatalysts with fast water dissociation kinetics. Nat. Commun. 2017, 8, 15437. [CrossRef] [PubMed]

12. Chen, Y.Y.; Zhang, Y.; Zhang, X.; Tang, T.; Luo, H.; Niu, S.; Dai, Z.H.; Wan, L.J.; Hu, J.S. Self-templated fabrication of $\mathrm{MoNi}_{4} / \mathrm{MoO}_{3-X}$ nanorod arrays with dual active components for highly efficient hydrogen evolution. Adv. Mater. 2017, 29, 1703311. [CrossRef] [PubMed]

13. McCrory, C.C.; Jung, S.; Ferrer, I.M.; Chatman, S.M.; Peters, J.C.; Jaramillo, T.F. Benchmarking hydrogen evolving reaction and oxygen evolving reaction electrocatalysts for solar water splitting devices. J. Am. Chem. Soc. 2015, 137, 4347-4357. [CrossRef] [PubMed]

14. McCrory, C.C.; Jung, S.; Peters, J.C.; Jaramillo, T.F. Benchmarking heterogeneous electrocatalysts for the oxygen evolution reaction. J. Am. Chem. Soc. 2013, 135, 16977-16987. [CrossRef] [PubMed]

15. Jin, Y.S.; Yue, X.; Shu, C.; Huang, S.L.; Shen, P.K. Three-dimensional porous $\mathrm{MoNi}_{4}$ networks constructed by nanosheets as bifunctional electrocatalysts for overall water splitting. J. Mater. Chem. A 2017, 5, 2508-2513. [CrossRef]

16. McKone, J.R.; Sadtler, B.F.; Werlang, C.L.; Lewis, N.S.; Gray, H.B. Ni-Mo nanopowders for efficient electrochemical hydrogen evolution. ACS Catal. 2013, 3, 166-169. [CrossRef]

17. Fang, M.; Guo, W.; Dong, G.F.; Xia, Z.M.; Yip, S.P.; Qin, Y.B.; Qu, Y.Q.; Ho, J.C. Hierarchical NiMo-based 3D electrocatalysts for highly-efficient hydrogen evolution in alkaline conditions. Nano Energy 2016, 27, 247-254. [CrossRef]

18. Jothi, P.R.; Kannan, S.; Velayutham, G. Enhanced methanol electro-oxidation over in-situ carbon and graphene supported one dimensional $\mathrm{NiMoO}_{4}$ nanorods. J. Power Sources 2015, 277, 350-359. [CrossRef]

19. Kuang, P.Y.; Tong, T.; Fan, K.; Yu, J.G. In situ fabrication of Ni-Mo bimetal sulfide hybrid as an efficient electrocatalyst for hydrogen evolution over a wide $\mathrm{pH}$ range. ACS Catal. 2017, 7, 6179-6187. [CrossRef]

20. Wertheim, G.K.; Wernick, J.H.; Crecelius, G. Surface effects on valence in rare-earth intermetallic compounds. Phys. Rev. B 1978, 18, 875. [CrossRef]

21. Roustila, A.; Severac, C.; Chêne, J.; Percheron-Guégan, A. Hydrogen effects on the electronic and microstructural properties of $\mathrm{Ce}, \mathrm{Ni}$, and $\mathrm{CeNi}_{2}$ intermetallic compound. Surf. Sci. 1994, 311, $33-44$. [CrossRef]

22. Lebugle, A.; Axelsson, U.; Nyholm, R.; Mårtensson, N. Experimental $L$ and $M$ core level binding energies for the metals ${ }^{22} \mathrm{Ti}$ to ${ }^{30} \mathrm{Zn}$. Phys. Scr. 1981, 23, 825-827. [CrossRef]

23. Brainard, W.A.; Wheeler, D.R. An XPS study of the adherence of refractory carbide silicide and boride rf-sputtered wear-resistant coatings. J. Vac. Sci. Technol. 1978, 15, 1800-1805. [CrossRef]

24. Bianchi, C.L.; Cattania, M.G.; Villa, P. XPS characterization of Ni and Mo oxides before and after "in situ" treatments. Appl. Surf. Sci. 1993, 70, 211-216. [CrossRef]

25. Takano, I.; Isobe, S.; Sasaki, T.A.; Baba, Y. Nitrogenation of various transition metals by $\mathrm{N}^{+}{ }_{2}$-ion implantation. Appl. Surf. Sci. 1989, 37, 25-32. [CrossRef] 
26. Conway, B.E.; Tilak, B.V. Interfacial processes involving electrocatalytic evolution and oxidation of $\mathrm{H}_{2}$, and the role of chemisorbed H. Electrochim. Acta 2002, 47, 3571-3594. [CrossRef]

27. Zheng, Y.; Jiao, Y.; Zhu, Y.H.; Li, L.H.; Han, Y.; Chen, Y.; Du, A.J.; Jaroniec, M.; Qiao, S.Z. Hydrogen evolution by a metal-free electrocatalyst. Nat. Commun. 2014, 5, 3783. [CrossRef] [PubMed]

28. Liang, Z.X.; Ahn, H.S.; Bard, A.J. A study of the mechanism of the hydrogen evolution reaction on nickel by surface interrogation scanning electrochemical microscopy. J. Am. Chem. Soc. 2017, 139, 4854-4858. [CrossRef] [PubMed]

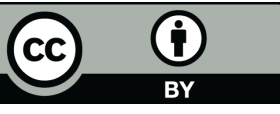

(C) 2018 by the authors. Licensee MDPI, Basel, Switzerland. This article is an open access article distributed under the terms and conditions of the Creative Commons Attribution (CC BY) license (http:// creativecommons.org/licenses/by/4.0/). 